Georgia State University

ScholarWorks @ Georgia State University

World Languages and Cultures Faculty

Publications

Department of World Languages and Cultures

2019

\title{
The control, content, and consequences of edTPA: World language teacher educators' perceptions
}

\author{
Susan A. Hildebrandt \\ Illinois State University, shildeb@ilstu.edu \\ Peter Swanson \\ Georgia State University, peters@tribcsp.com
}

Follow this and additional works at: https://scholarworks.gsu.edu/mcl_facpub

Part of the Other Languages, Societies, and Cultures Commons

\section{Recommended Citation}

Hildebrandt, Susan A. and Swanson, Peter, "The control, content, and consequences of edTPA: World language teacher educators' perceptions" (2019). World Languages and Cultures Faculty Publications. 82. https://scholarworks.gsu.edu/mcl_facpub/82

This Article is brought to you for free and open access by the Department of World Languages and Cultures at ScholarWorks @ Georgia State University. It has been accepted for inclusion in World Languages and Cultures Faculty Publications by an authorized administrator of ScholarWorks @ Georgia State University. For more information, please contact scholarworks@gsu.edu. 


\title{
TITLE
}

The control, content, and consequences of edTPA: World language teacher educators' perceptions

\section{AUTHOR \& AFFILIATION}

Susan A. Hildebrandt

Illinois State University

Pete Swanson

Georgia State University / United States Air Force Academy

\begin{abstract}
Implemented in more than 870 teacher education programs across 41 states and the District of Columbia, edTPA is marketed as a content-specific, standardized portfolio assessment of beginning teacher performance. However, concerns about edTPA and its content-specificity are pervasive. To that end, the researchers surveyed teacher educators with World Language edTPA experience $(\mathrm{N}=88)$ to ascertain their perceptions of the assessment, including its impact on teacher candidates, teacher education programs, and clinical placements, as well as the resources required, support experienced, and consequences perceived as a result of its implementation. Using Cochran-Smith et al.’s (2018) framework of teacher education accountability, the researchers explore issues of control, content, and consequences related to power relationships and the World Language edTPA, centering on the assessment's intended content-specificity, while recounting an ACTFL task force's efforts in 2016 to influence the assessment's content.
\end{abstract}




\section{Introduction}

Given its rapid expansion to more than 870 university teacher education programs in 41 states and the District of Columbia (American Association of Colleges for Teacher Education, AACTE, 2019), the teacher performance assessment called edTPA has prompted discussions across the 28 content areas for which edTPA handbooks exist and teacher candidates seek certification. Designed around "the context of the subject-matter content and learning goals" (Sato, 2014, p. 429) and "authentic teaching situations" (p. 422), the assessment's content sets high expectations and the impact is far reaching. Specifically, edTPA was designed to offer a standardized means of measuring teacher readiness based on candidates' performance in actual classrooms working independently with real and diverse students, rather than by passing a multiple-choice measure of discrete professional knowledge or the ability to apply that knowledge to hypothetical situations with limited context. edTPA, which is administered and scored externally from candidates' teacher preparation institutions at a cost of $\$ 300$ per portfolio submission, was created by The Stanford Center for Assessment, Learning, and Equity (SCALE), in collaboration with AACTE. edTPA's developers describe it as an authentic, content-specific assessment tool that shows how teacher candidates develop and evaluate student learning (SCALE, 2017a). To demonstrate that they can complete the three-step teaching cycle (planning, instruction, and assessment), teacher candidates must plan a learning segment of three to five lessons, record 15 minutes of instruction, analyze student learning data, and justify their own pedagogical decisions through three extensive written commentaries. The World Language (WL) edTPA is scored using 13 five-point Likert scale rubrics that span those same three tasks: Planning for Instruction and Assessment (Rubrics 1, 2, 3, 4), Instructing and Engaging Students in Learning (Rubrics 5, 6, 7, 8, 9), and Assessing Student Learning (Rubrics 10, 11, 12, 13). 
A number of studies have highlighted the assessment's potential to effectively assess aspiring teachers' knowledge and skills across varying subjects (Youngs \& Whittaker, 2015) but edTPA has motivated only a modest amount of content-specific research interest, with the exception of, for example, An (2017) in elementary education; Castellano, Duckor, \& Wihardini (2016) in elementary mathematics; and Heil and Berg (2017) in music education. In contrast, the impact of the WL edTPA on WL teacher education programs seems to have provided a rich area of investigation (e.g., Behney, 2016; Hildebrandt \& Swanson, 2014; Jourdain, 2018a, 2018b; Kissau \& Algozzine, 2017; Okraski \& Kissau, 2018; Russell \& Davidson Devall, 2016; Swanson \& Hildebrandt, 2018; Troyan \& Kaplan, 2015). The present study sought to supplement that existing literature by investigating WL teacher educators' perceptions of edTPA and its impact on WL teacher education programs. Specifically, the researchers explored in depth three dimensions of Cochran-Smith et al.'s (2018) eight-dimension teacher education accountability framework: control, content, and consequences.

\section{Literature Review}

\section{Educational Reform}

Since the 1960's, questions about teacher attributes, effectiveness, knowledge, and, in particular, outcomes have driven educational reform in the United States (U.S., Cochran-Smith, 2001). Defining and measuring learning outcomes has occupied the thinking and practice of teacher educators, teacher candidates, K-12 administrators, and legislators since the No Child Left Behind Act (2002) required the use of content tests to measure teacher candidates' knowledge in 2001. In recent years, state legislatures have emphasized teacher education program accountability, thus promoting efforts to measure how well teacher candidates are likely to perform in the classroom. Because varying stakeholders have traditionally defined acceptable 
levels of teacher candidate performance according to local programmatic, university, and state policies and practices, and thus teacher candidates' learning experiences and assessments of their knowledge and skills frequently differ from one context to another, edTPA emerged in recent years as a response to "rising uncertainty about the consequences of accountability" (CochranSmith et al., 2018, p. 5) and a means to standardize the assessment of beginning teacher performance across contexts. In that way, the assessment provides an authentic measure of teaching ability that is independent of the state and university in which a preservice teacher is educated, thus allowing program and university outcomes to be compared across contexts.

The standardization that edTPA offers may attract state legislatures who attempt to document how well their state's teacher candidates and teacher preparation programs meet federal expectations and fulfill other accountability measures; edTPA also gives them the ability to compare educator preparation programs within and across states. For these reasons, among others, 18 of the 41 states in which edTPA is used currently base, or will soon be used, base, individual candidates' teacher licensure decisions on edTPA scores (AACTE, 2018). In addition, edTPA scores are frequently used as part of state, regional, or professional (e.g., Council on the Accreditation of Educator Preparation [CAEP]) accreditation processes to measure the effectiveness of teacher preparation programs and institutions and determine whether those bodies merit accreditation. Thus, edTPA pass rates impact both individual teacher candidates as well as universities and departments, as those bodies seeks to recruit and support aspiring teacher candidates during a nationwide shortage and recommend them for certification.

\section{Evaluating Educational Reforms}

To better understand the evolution of teacher education reforms, Cochran-Smith (2001) posed two fundamental questions about outcomes and accountability in teacher education: "What 
should the outcomes of teacher education be for teacher learning, professional practice, and student learning?" and "How, by whom, and for what purposes should these outcomes be documented, demonstrated, and/or measured?” (pp. 12-13). More recently, Cochran-Smith et al. (2018) considered the underlying assumptions of the teacher education accountability movement, the problems that particular reforms are designed to address, and the power relationships in which reforms operate, outlining a framework to make sense of teacher education accountability. Their framework consists of eight individual dimensions across three thematic clusters.

The first thematic cluster unpacks the foundations of accountability, or the "principles, intentions, and concepts underlying accountability" (Cochran-Smith et al., 2018, p. 40), by examining the values, purposes, and commonsense concepts of various educational reform efforts. In their examination of the edTPA in general, Cochran-Smith et al. concluded that its foundational values highlight teacher candidates' and K-12 students' preparation for the workplace, professionalization of teaching supported by demanding standards, and positive washback from the assessment of teacher preparation programs. Their analysis further pointed to edTPA's purposes, including standardizing the assessment of teacher candidate performance and improving teacher education. Furthermore, they concluded that edTPA's foundational concepts support a constructivist view of teaching, incorporate varied measures of success, take into consideration the situational nature of teaching and learning, and respond to a call for highquality assessments to ensure that only well-prepared teacher candidates are accepted into the profession.

Cochran-Smith et al.'s (2018) second thematic cluster focuses on the problem that an assessment, like edTPA, seeks to diagnose and resolve. Recognizing that educational policy represents only one component within a much larger system, they contend that the edTPA 
designers sought to diagnose the problem — that " $[\mathrm{u}]$ neven teaching and teacher education quality combined with lack of professional standards results in inconsistent teaching quality and the low status of the teaching profession" (Cochran-Smith et al., 2018, p. 118). As a remedy, they attempted to create a "[u]niform and authentic" (p. 118) assessment of teacher readiness in order to improve teacher education through "actionable data" (p. 118).

Cochran-Smith et al.'s (2018) third cluster unpacks the political nature and power relationships of teacher education, acknowledging that teacher education policies are not without bias and focusing attention on questions of (1) Control (who makes decisions related to teacher accountability), (2) Content (what is acceptable evidence of programs having met imposed requirements), and (3) Consequences of implemented policies on various stakeholders. The authors argue that "[a] major part of the controversy about edTPA involves power and control, particularly who represents or speaks for the profession" (Cochran-Smith et al., 2018, p. 150).

The control dimension (Cochran-Smith et al., 2018) pertains to aspects of edTPA that are external to, and thus beyond the control of, teacher education programs. For example, SCALE and Pearson - a multinational corporation with an infrastructure in place to administer and score the assessment nationwide - influence at least in part the kind of evidence that is required and the scores. Additionally, states legislatures or departments of education determine what score constitutes acceptable evidence of beginning teacher performance on edTPA for both individual teacher licensure and program completion decisions.

Power relationships are further evident in edTPA content, which is meant to demonstrate that candidates are prepared for teaching from their first day in the classroom and to hold teacher education programs accountable if their candidates are not. Cochran-Smith et al.'s (2018) analysis describes edTPA's creation as "internal to the profession” (p. 118), reinforcing 
SCALE's contention that edTPA was created "for the profession, by the profession" (SCALE, 2015, p. 4). Each of the 28 different content areas has its own edTPA handbook that provides the general structure and expectations of the given subject area, with $80 \%$ of its content shared with all other subjects' handbooks and $20 \%$ of its content from 'key subject-specific components of teaching and learning drawn from the content standards for student learning and pedagogical standards of national organizations" (SCALE, 2015, p. 5). That content, assessed through the use of "standard, subject-specific rubrics" (Cochran-Smith et al., 2018, p. 118), along with its nationwide standing, makes edTPA appealing for teacher accountability purposes. In the case of WLs, the edTPA World Language Assessment Handbook (SCALE, 2017a) states that it is "[c]onsistent with the World-Readiness Standards for Learning Languages developed by the American Council on the Teaching of Foreign Languages... and the ACTFL/CAEP Program Standards for the Preparation of Foreign Language Teachers” (SCALE, 2017a, p. 1). Specifically, the WL edTPA evaluates teacher candidates' abilities to help students to develop communicative proficiency in meaningful cultural context(s) (SCALE, 2017a).

Although edTPA “is leagues better than any pencil-and-paper test could be” (Au, 2013, p. 22), content-specific challenges that appear to be particular to WL teaching and teacher education exist, which is a cause for concern in an era of ongoing nationwide K-12 WL teacher shortage. Over a four-year period (2014 to 2017, SCALE, 2015, 2016, 2017b, 2018), the number of WL edTPA portfolios submitted for review increased from 416 to 655 , while the total mean scores on the assessment declined slightly more than $10 \%$ or 4.10 points (Hildebrandt \& Swanson, in press), from 40.00 in 2014 to 35.90 in 2016, with decreasing means for each of the three tasks. For example, on Rubric 8 (Subject-Specific Pedagogy, which has been shown to be somewhat problematic; Hildebrandt \& Swanson, 2016), there was a notable decrease from 2.40 
to 1.90 from 2014 to 2017 (SCALE, 2015, 2016, 2017b, 2018). It has been suggested that the rubric's expectations - that beginning teachers demonstrate the ability to engage learners in analyzing the perspectives, products, and practices of the Cultures goal area and help them to make Comparisons with their home cultures in a 15-minute video - may be unreasonable (e.g., Hildebrandt \& Swanson, 2016). In addition, questions have arisen about edTPA's assertions of authenticity, particularly in teaching fields with smaller numbers of teacher candidates, like WLs, since "edTPA does not account for variations in individual test-takers or teacher education programs" (Cochran-Smith et al., 2018, p. 125). These content-specific challenges can impact teacher candidate scores and, thereby, their chances at licensure and their preparation program's possibilities of accreditation.

The intended and unintended consequences of a particular educational reform are also addressed in the third cluster of the Cochran-Smith et al. (2018) framework. Although passing edTPA is generally intended to mean that teacher candidates meet the standards contained in the assessment and, thereby, achieve licensure or certification in their state, the assessment may unintentionally diminish diversity within the teacher candidate population. For example, it has been pointed out that teacher candidates who are native and heritage speakers of Spanish, rather than English, struggle to complete the lengthy required commentaries and thus may not be able to enter the language teaching profession (Jourdain, 2018a, 2018b; Russell \& Davidson Devall, 2016, 2018).

Taken as a whole, the three thematic clusters (Control, Content, and Consequences) and the eight dimensions of the Cochran-Smith et al. (2018) framework allow stakeholders to "unpack and interrogate accountability regulations and policies by drilling beneath the surface level of rhetoric and highly politicized debate" (Cochran-Smith et al., 2018, p. 34). Specifically, 
stakeholders across the 28 edTPA content areas can use the framework to analyze the unique interplay among the eight dimensions as they are manifested in each content-specific edTPA handbook and their state and university teacher education, accountability, and accreditation milieu.

\section{Teacher Educators' Perspectives of edTPA}

Decades of teacher education reform and the use of standardized assessments of teacher knowledge and performance have prompted a variety of reactions from teacher educators. However, given edTPA's relatively recent emergence as a widespread force in American education, studies of teacher educators' perspectives represent a relatively recent area of investigation. Picower and Marshall (2017), for example, surveyed 183 teacher educators from 14 states about edTPA's impact on teacher preparation related to social justice; they found that teacher educators perceived that edTPA had promoted teacher education's corporatization, a limited definition of teaching, a diminished focus on multiculturalism, and a decrease in the number of teacher candidates of color. Davis and Armstrong (2018) interviewed 17 teacher educators from 11 different content areas at a regional public university about edTPA. They found a love-hate relationship, which included positive impressions of the reflection, video, and academic language components of edTPA and negative impressions of its lack of focus on classroom management and pre-post testing. Specific to WLs, Hildebrandt and Swanson (2016) shared a range of voices from the field, including four WL teacher educators who held faculty positions, two mentor teachers, and one university supervisor, all of whom highlighted the WL edTPA focus on backward design, teacher performance, and reflection but shared concerns about its effectiveness as a tool to evaluate WL teacher candidate performance, the lack of WL-specific 
model portfolios, diminished performance by teacher candidates whose first language was not English, technological challenges, excessive cost, and pressing timelines.

To augment this modest body of previous work on educators' perceptions of the WL edTPA, the present study focused on the content-specific version of the national assessment, as it plays out within the multilayered hierarchy of the teacher preparation accountability system (e.g., local control, state and federal legislation). Specifically, the study investigated WL teacher educators' perceptions of the way in which one of Cochran-Smith et al.'s (2018) three thematic clusters - the power relationships - and its three component dimensions - control, content, and consequences - were manifested within the context of the high-stakes, subject-specific assessment, the WL edTPA.

\section{Methods}

\section{Instrument}

The authors, on behalf of the ACTFL edTPA Task Force, developed a survey based initially on Picower and Marshall's (2017) survey and further informed and revised to incorporate input from the existing literature (e.g., Greenblatt, 2016; Hildebrandt \& Swanson, 2014, 2016; Jourdain, 2018a; Russell \& Devall, 2016; Swanson \& Hildebrandt, 2018), pertinent scholarly presentations, and discussions at academic conferences. ACTFL Task Force members served as subject matter experts and provided feedback on initial survey items in order to strengthen content validity and group items into categories. After revisions, the researchers independently completed an item content analysis by assigning items to one of the three dimensions (Content, Control, Consequences), resulting in $96.2 \%$ agreement. The one item on which initial agreement was not achieved was resolved through discussion. In this way, the 26 Likert scale statements (provided in Tables 1, 2, and 3) were grouped by theme to investigate 
participants' views of edTPA as related to: 1) content (items, 1, 2, 6, 16, 17, 18, 21, 25, 26), 2)

control (items 3, 4, 5, 15, 19, 20, 22, 23, 24), and 3) consequences (items 7, 8, 9, 10, 11, 12, 13, and 14). Participants were asked to respond to each statement using a 6-point Likert scale from 1 (Strongly Disagree) to 6 (Strongly Agree), Demographic items were also included at the end of the survey.

\section{Procedures}

Following approval by the American Council on the Teaching of Foreign Languages (ACTFL) and the first author's university-specific Institutional Review Board, a call to participate in an online survey about the WL edTPA, shared online via Qualtrics, was sent to members of the ACTFL Teacher Development Special Interest Group (SIG) in March 2018. Although the survey was shared through the ACTFL SIG, participants were not required to be either ACTFL or Teacher Development SIG members in order to participate. After sending several follow-up emails, data collection ended in June 2018. Data were analyzed using SPSS 25.0. Given the nature of the research question, only measures of central tendency are reported.

\section{Participants}

One hundred and nine collegiate faculty responded to the invitation to participate in the study. Responses from several participants were eliminated either because they listed 0 as the number of years of experience with edTPA or because their responses were incomplete, primarily after answering only the first few items and providing no demographic information. Responses from 88 participants from $19^{\mathrm{i}}$ of the 41 states and District of Columbia in which teacher education programs currently use edTPA (AACTE, 2019) remained. Participants ranged in age from 22 to 80 years old $(M=50.36, S D=12.24)$, and females $(n=68)$ outnumbered males $(n=20)$. Approximately three-quarters of the participants self-reported their ethnicity as 
Caucasian/white followed by Latino/a (9\%), African American $(n=1 \%)$, Asian $(n=4 \%)$, Multiracial $(n=1 \%)$, and Other $(n=5 \%)$. Participants reported having worked in the WL teaching profession for an average of 21.51 years $(S D=12.17)$ and having prepared teacher candidates to teach various languages, primarily French, German, and Spanish, although other languages such as Chinese, Hebrew, and Italian were also represented. Nearly all participants reported holding more than one role at their institution, with the majority $(n=73)$ reporting that they worked as WL methods instructors, and/or served as student teacher supervisors $(n=63)$ and/or program directors $(n=34)$. Thirteen reported fulfilling another unidentified role (Other) at their institution in addition to holding at least one or more of the three specific roles listed in the survey. Participants reported having worked with the WL edTPA for an average of 3.65 years $(S D=1.66)$. Twelve participants $(13.6 \%)$ reported being certified edTPA portfolio evaluators.

\section{Findings}

Survey data presented below are organized according to the three dimensions of the Cochran-Smith, et al. (2018) framework related to power relationships in teacher education accountability (i.e., Content, Control, and Consequences).

\section{Control}

As shown in Table 1, concerning control and "jurisdictional issues" (Cochran-Smith, et al., 2018, p. 41), participants generally reported being modestly supported by either their institution or their department, and felt slightly more support from their institution Table 1

Means and standard deviations for items related to control. 
3. I feel supported by my institution with respect to the World Language edTPA.

4. I feel supported by my department with respect to the World Language edTPA.

5. I feel supported by the developers of the World Language edTPA in order to better prepare my teacher candidates for this assessment.

$3.18 \quad 1.57$

15. I believe the inclusion of corporations such as Pearson into education is helping develop better language teachers.

$2.00 \quad 1.10$

19. SCALE (the developers of edTPA) has been responsive to $\quad 2.84$ my concerns about edTPA.

20. edTPA diminishes local teacher educator influence by ignoring local expertise.

$4.12 \quad 1.48$

22. The edTPA cut score required in my context is reasonable.

23. The pass rates for my teacher candidates on edTPA are acceptable.

24. I have access to my teacher candidates' edTPA scores.

(item $3 ; M=4.78, S D=1.11$ ) than by their department (item $4 ; M=4.45, S D=1.42$ ).

Participants felt that less support was offered by edTPA developers (item $5 ; M=3.18, S D=$ 1.57) and that SCALE was even less responsive to their concerns (item $19 ; M=2.84, S D=1.30$ ). Participants agreed that edTPA diminished teacher educators' influence by ignoring local expertise (item $20 ; M=4.12, S D=1.48$ ) and disagreed that the inclusion of corporations such as Pearson into education helped to develop better language teachers (item $15 ; M=2.00, S D=$ 1.10).

Turning to the idea of the WL edTPA cut scores, participants' responses were more neutral concerning the scores set in their states (item $22 ; M=3.05, S D=1.55$ ), and they 
generally agreed that their teacher candidates' pass rates were acceptable (item $23 ; M=3.97, S D$ $=1.26)$. They also reported that they generally had access to their teacher candidates' edTPA scores (item 24; $M=4.41, S D=1.11$ ). Apart from Items 3 and 15, as shown in Table 1 , however, the standard deviations for many of the items related to control were rather large, suggesting a heterogeneity of participant responses.

\section{Content}

With respect to the participants' views of the content of edTPA (see Table 2), participants agreed that both they and their teacher candidates had a good understanding of the WL edTPA (item $1 ; M=5.14, S D=0.97$; item $2 ; M=4.58, S D=1.03$ ). However, they were neutral to slightly negative when asked if edTPA represented a better assessment of novice teacher quality than what their programs required before edTPA's implementation (item $6 ; M=3.11, S D=$ Table 2

Means and standard deviations for items related to content.

2. My teacher candidates have a good understanding of what they are expected to do with respect to the World Language edTPA.

6. I believe that edTPA is a better assessment of novice teacher quality than what our program required before the implementation of edTPA. 
17. edTPA has changed the focus of our methods classes for the better.

18. edTPA has changed the focus of my teacher candidates' clinical experiences for the better.

21. I feel that edTPA is a reliable assessment of novice teacher performance. teacher candidate success in the profession.

1.67). Concerning the impact of edTPA on the content of their programs, participants generally disagreed that edTPA had changed the focus of their teacher education program as a whole (item $16 ; M=2.94, S D=1.45$ ), of the methods classes (item $17 ; M=2.84, S D=1.46$ ), or of teacher candidates' clinical experiences for the better (item $18 ; M=2.82, S D=1.45$ ). They were undecided about edTPA's reliability (item $21 ; M=3.23, S D=1.60$ ), although they generally agreed that their teacher candidates excelled on the WL edTPA (item $25 ; M=4.43, S D=1.48$ ) and that the WL edTPA was a good measure of candidate professional success (item 26; $M=$ 4.10, $S D=1.23$ ). Apart from items 1 and 2, most of the survey statements in this section also had rather large standard deviations, indicating that the participants' perceptions were not homogenous.

\section{Consequences}

Turning to consequences, both intentional and unintentional, analyses revealed that participants were much stronger in their agreement that the WL edTPA was time-consuming for 
teacher candidates (item $7 ; M=5.33, S D=0.93$ ) and for faculty members (item $8 ; M=5.14, S D$ = 0.97). Participants also agreed that their teacher candidates had difficulty preparing for the WL Table 3

Means and standard deviations for items related to consequences.

$M \quad S D$

7. The World Language edTPA is time-consuming for the $5.72 \quad 0.57$ teacher candidates.

8. The World Language edTPA is time-consuming for faculty $\quad 5.33 \quad 0.93$ members.

9. The cooperating teachers (i.e., the in-service teachers working with our student teachers) express concerns about the World

Language edTPA to faculty.

10. The cooperating teachers (i.e., the in-service teachers working with our student teachers) express concerns about the $4.38 \quad 1.14$ World Language edTPA to teacher candidates.

11. The $\$ 300$ cost for the World Language edTPA is a fair price for the assessment.

12. My teacher candidates have difficulty preparing the World Language edTPA portfolio while student teaching.

13. Teacher candidate enrollment in my program has dropped because of the requirement to complete the World Language edTPA.

$3.13 \quad 1.52$

14. Since edTPA became a requirement, it is more challenging 3.36 1.46 to place student teachers in schools.

edTPA while student teaching (item $12 ; M=5.06, S D=1.10$ ) and generally disagreed that the $\$ 300$ cost represented a fair cost (item $11 ; M=2.00, S D=1.10$ ). Participants generally agreed that in-service teachers working with their teacher candidates expressed concerns to both faculty members (item $9 ; M=4.35, S D=1.30$ ) and to teacher candidates (item $10 ; M=4.38, S D=1.14$ ) 
about the WL edTPA, although they slightly disagreed that their programs had experienced a drop in enrollment (item $13 ; M=3.13, S D=1.52$ ) and that it had become more challenging to place student teachers in schools (item $14 ; M=3.36, S D=1.46$ ) since edTPA became a requirement.

\section{Summary}

When examining the 26 items as a whole, rather large standard deviations indicated that participants did not unanimously endorse the WL edTPA. The statements for which the highest level of agreement were reported addressed the time-consuming nature of edTPA for teacher candidates (item 7) and faculty members (item 8), the difficulty candidates experienced student teaching and preparing edTPA at the same time, (item 12) and participants' understanding of the WL edTPA (item 1).The statements with the overall highest levels of disagreement concerned the inclusion of corporations like Pearson in teacher education (item 15) and the fairness of the cost (item 15).

\section{Discussion}

The sophisticated interrelationship among stakeholders — which include but are not limited to teacher candidates, faculty members in world language departments and teacher education programs, cooperating teachers, learners and their parents, federal and state governments, accreditation agencies, and the creators and administrators of edTPA — has developed as part of the current teacher education accountability paradigm. As part of that dominant paradigm, teacher education programs in 41 states and the District of Columbia use edTPA to make programmatic and licensure decisions (AACTE, 2019). This study explored how WL teacher educators who have experience implementing the WL edTPA viewed the assessment using Cochran-Smith et al.'s (2018) lens of power relationships. Focusing specifically on WL 
educators' perceptions concerning the third of the framework's three clusters - power relationships - the study specifically investigated the control exerted over the WL edTPA ("who decides"), the content of this high-stakes assessment ("what counts"), and the consequences of its use ("what happens") (Cochran-Smith et al., 2018, p. 41).

This discussion takes an activist stance. Specifically, it situates the findings concerning control, content, and consequences within the existing literature on teacher education accountability systems, suggests ways in which the assessment and its implementation could be improved, documents the ACTFL edTPA task force's efforts to improve the WL edTPA handbook, and shares the extent to which SCALE has been willing to take into consideration suggestions from the language teaching profession.

\section{Control}

In the 1980s, A Nation at Risk (National Commission on Excellence in Education, 1983) raised the alarm that U.S. children were not being educated to be globally competitive and that teacher quality was the single most influential variable impacting student achievement. The perceived need for teacher accountability continued with No Child Left Behind in 2001, and teacher effectiveness became the central focus of U.S. educational policy. Given the focus on outcomes inherent in these reforms' (Cochran-Smith, 2001), control emerged as one major undercurrent of the teacher education accountability movement, leading to the widespread use of high-stakes assessments of novice teachers' knowledge and skills. Those assessments required that teacher education programs adjust to the new accountability-oriented landscape: As noted by Cochran-Smith et al., (2018), who decides what counts and how to measure it are at the heart of this discussion. Since its relatively recent arrival on the national stage, edTPA has spread at an unprecedented rate from 27 states and the District of Columbia in 2013 (Hildebrandt \& Hlas, 
2013) to 36 states and the District of Columbia in 2016 (Hildebrandt \& Swanson, 2016) to 869 educator preparation programs in 41 states and the District of Columbia (AACTE, 2019). Participants in this study work with teacher candidates whose teaching futures are thus controlled, at least in part, by state legislatures who determine whether edTPA will be used and ultimately what the acceptable edTPA cut scores for licensure or accreditation will be.

In addition, since the introduction of edTPA on the national educational stage, questions have arisen regarding who is in control of WL teacher evaluation in the U.S. and Pearson's role "has been among the most controversial aspects of edTPA," according to Cochran-Smith, et al. (2018, p. 113). The data from the present study, with some exceptions, do not reflect homogenously favorable opinions among WL teacher educators who have experience working with the WL edTPA: Support from their department and edTPA developers, along with SCALE's responsiveness to their concerns were not rated on the positive side of the scale. Participants perceived that edTPA diminished the influence of local teacher educators; they were ambivalent about the pass rates, cut scores, and access to those scores. While participants reported more uniform, positive opinions concerning the support that was offered by their institutions, they voiced consistently negative opinions about the inclusion of corporations into education, a finding that corroborates other studies of teacher educators' perceptions (e.g., Picower \& Marshall, 2017). Although edTPA was initially lauded as a bar exam for novice educators (Au, 2013; Hutt, Gottlieb, \& Cohen, 2018) that sought to professionalize teaching, some argued that it has diminished and devalued local control of teacher preparation in the U.S. (Croft, Robbins, \& Stenhouse, 2013; Greenblatt, 2016). Finally, some researchers have found that it also diminishes professional control (Croft, Robbins, \& Stenhouse, 2013; Greenblatt, 2016). Furthermore, conversations with the center's personnel about the WL edTPA indicates 
that SCALE has not clearly heard concerns raised by an ACTFL task force regarding the assessment, a point that is further developed below.

\section{Content}

The creators of edTPA state that the assessment was created "for the profession, by the profession" (SCALE, 2015, p. 4). However, in 2016, an ACTFL edTPA Task Force, co-chaired by the authors, approached SCALE staff to raise content-specific concerns at the point when the WL edTPA handbook was scheduled for revision. Those conversations, established through a series of emails and three conference calls, highlighted several discrepancies between the WL edTPA and the language profession's expectations for education and teacher candidates, in an effort to make the assessment more effective. For example, the task force pointed out that requiring an experienced teacher to carry out the performance described in Rubric 8 (SubjectSpecific Pedagogy) to a satisfactory degree is not realistic, given that all three Ps of the Cultures goal area (Perspectives, Practices, and Products) from The World-Readiness Standards for Language Learning (The National Standards Collaborative Board, 2015) must be addressed within 15 minutes of videotaped teaching and response to one prompt in the instruction task commentary (SCALE, 2017a). Furthermore, it was noted that such high expectations are even less realistic for a novice teacher. The task force members also addressed additional requirements in that particular rubric that are illogical for a novice teacher, but which the authors are hesitant to note here in the interest of test security. Discrepancies about teacher candidate target language use were also discussed. Following each conference call, task force members were optimistic that SCALE personnel were receptive to the suggested changes and that they would be made to the handbook; unfortunately, those suggestions resulted in merely cosmetic changes (e.g., 
clarification of the three modes of communication, bolding particular portions of some rubrics), which can be found in a comparison of the 2016 and 2018 versions of the WL edTPA handbook. Additional concerns about content-specific expectations focused on the evaluation process. Although external reviewers were described as having "content-specific expertise" (Youngs \& Whittaker, 2015, p. 97), the experiences required to be employed by Pearson (2018) remain vague, and it is unknown if external reviewers have up-to-date language teaching pedagogies to draw upon as they score (Swanson \& Hildebrandt, 2017) and the "lack of transparency related to scorer qualifications challenge[s] the WL teacher education community and teacher candidates who were taught in their methods classes to teach language in communicative ways that may not be rewarded in the evaluation of their portfolios" (Swanson \& Hildebrandt, in press, p. TBD). Content-specific expertise may mean different things to different stakeholders and, without knowledge of who the members of the profession are that evaluate edTPA portfolios, it is difficult to determine "what counts as valid and reliable" (Cochran-Smith et al., 2018, p. 41) content.

With regard to the Content dimension of the WL edTPA, participants in this study were ambivalent. They did not confirm that edTPA was an effective measure of teacher candidate success, that is was a more reliable, or a better, assessment than the instrument that their university had previously used; interestingly, this was true whether their candidates excelled or not. What is more, they did not confirm edTPA's washback: the assessment's impact on their teacher education programs, methods classes, or clinical experiences was modest at best, which, in fact, represents a somewhat positive finding for the assessment developers, unlike Picower and Marshall's (2017) finding that use of edTPA diminished social justice and diversity topics in teacher education coursework. While participants agreed that both they and their candidates 
understood the expectations of the WL edTPA, WL teacher educators' collective perceptions of the content did not reflect unanimous and enthusiastic support.

In sum, the experiences of task force members suggest an uneven power dynamic between representatives of the national association of language teachers (i.e., the ACTFL Task Force) and an entity outside of the language teaching profession (i.e., SCALE). This relationship suggests that the subject-specific members of the profession do not have as much power over or input into the content the WL edTPA as documentation leads others to believe they have, or that they would have hoped to have. It thus remains unclear to many in the field why the substantial changes suggested by the task force in 2016 resulted in surface-level changes and why efforts to align the WL edTPA more closely with second language acquisition theory and communicative language teaching practices were, perhaps, met with misunderstanding by SCALE's general personnel (i.e., non-language teaching). The content of the WL edTPA thus remains troublesome to many in the language teaching profession.

\section{Consequences}

For the past several decades, "multiple co-existing accountability initiatives, policies, and mechanisms" (Cochran-Smith et al., 2018, p. 38) have divided teacher educators' attention and raised stakes at a variety of levels for teacher education institutions and programs. Teacher education faculty, teacher candidates, and cooperating teachers have had to be flexible in an era when expectations for beginning teacher readiness continue to shift. The intentional and unintentional "results, effects, impacts, and implications" (p. 41) - the consequences - of these changes make up the final dimension of Cochran-Smith et al.'s (2018) power relationship framework cluster. 
In this study, the use of limited resources - time and money - was of particular concern. The time-consuming nature of edTPA, both for teacher candidates and for faculty, troubled participants in this study; this finding is consistent with the findings of other studies (Greenblatt, 2016; Hildebrandt \& Swanson, 2016; Picower \& Marshall, 2017). In particular, participants expressed concerned about the difficulty of preparing a WL edTPA portfolio while simultaneously developing the knowledge and skills during student teaching that are required of beginning teachers. Specifically, in order to receive feedback and have time to re-do a particular element of the edTPA during a 14 - 15-week student teaching practicum, the teacher candidate must complete and submit the portfolio by the midpoint of the semester, typically Week 8 and be prepared to re-do any task on which he or she is unsuccessful in a period of about 10 instructional days so that the new version can be submitted and re-evaluated-- at the cost of $\$ 100$ per task - prior to the end of the student teaching experience (Hildebrandt \& Swanson, 2016). If the teacher candidate does not pass the WL edTPA during that one-semester experience, he or she may need to complete a second student teaching placement - which in many institutions carries additional tuition and fees - and design, develop, and submit a new edTPA portfolio, at the cost of $\$ 300$. In an era of continuing and long-standing teacher shortages (Swanson \& Mason, 2018; U.S. Department of Education, 2017), high student debt (Pringle, 2019), and low entry-level teacher salaries, participants in this study were not unanimous in asserting that a cost of $\$ 300$ was appropriate, which is consistent with previous literature (Hildebrandt \& Swanson, 2016; Madeloni \& Gorlewski, 2013; Picower \& Marshall, 2017). It is thus probable that the financial burden of outsourcing beginning teacher evaluation increases teacher candidate costs and may diminish numbers of new teachers. Research on the WL edTPA has also shown that the assessment represents an unintended barrier to native/heritage language speakers becoming 
language teachers (Jourdain, 2018a, 2018b; Russell \& Davidson, 2018). What is more, since national data show that the mean WL edTPA composite scores have decreased (SCALE, 2015, 2016, 2017b, 2018), while the cut scores to pass the assessment in some states are scheduled to increase each year in many states (AACTE, 2018) edTPA may be a barrier for candidates across a range of profiles who hope to enter the profession (Hildebrandt \& Swanson, in press).

\section{Understanding Power in the Context of the WL edTPA}

Taken collectively, creating a nationalized, teacher performance assessment that allows stakeholders to compare teacher candidate performance across programs, states, and even the nation represents an admirable goal. However, care must be taken to ensure content validity by working directly with experts and specialized professional associations. While it cannot be determined if teacher candidates' scores would have more directly and appropriately reflected their actual knowledge and skills had SCALE acted on the ACTFL Task Force's suggested revisions, the authors, representing ACTFL and the task force, continue to advocate for a collaborative approach to improving the assessment so as to ensure that edTPA be a "contentspecific" measurement of teacher readiness developed for the profession by members of the profession. It is hoped that truly meaningful conversations among all stakeholders will result in a careful review of the assessment that leads to an improved version of the WL edTPA handbook that sets more realistic and accurate expectations for novice world language teachers.

\section{Limitations and Future Research}

While the findings pose important questions about the WL edTPA, several limitations should be considered. First, the data came from a national survey that included 88 participants from approximately half of the states in which edTPA $(N=19)$ is currently in use. Replicating the study with a larger number of participants would be necessary to confirm the study's 
findings. However, it must be remembered that WL teacher education programs tend to be small, WL teacher educators tend to work alone and carry multiple roles, and the number of dedicated WL teacher development specialists is declining (Garcia, Moser, \& Davis-Wiley, 2019). Second, self-reported data for participants who choose to respond to a survey may differ from those who decline that opportunity. Third, given the large standard deviations, survey results revealed that, with some exceptions, WL teacher educators did not express homogeneous views, perhaps reflecting the diversity of edTPA experiences and programmatic contexts within this particular group of participants. Notwithstanding these limitations, participants' responses did not express unequivocal support for the WL edTPA and significant concerns remain. Additional research that incorporates qualitative, quantitative and mixed methods approaches could explore other stakeholders' perceptions of edTPA (e.g., cooperating teachers, K-12 students). A broader sample of respondents is also called for.

\section{Conclusion}

In conclusion, the sudden appearance and broad implementation of edTPA on the national stage has stimulated discussion as well as research on the topic of novice teacher preparation and program accountability in the U.S. Consistent with a growing body of research that has revealed issues with the WL edTPA in particular (e.g., Behney, 2016; Hildebrandt \& Swanson, 2014; Jourdain, 2018a, 2018b; Kissau \& Algozzine, 2017; Russell \& Davidson Devall, 2016; Troyan \& Kaplan, 2015), it is hoped that SCALE will embrace partnerships with content experts and move toward a more collaborative model for holding teacher preparation institutions to high but attainable standards and expectations. As stated by Cochran-Smith et al. "joint decision making among relevant stakeholders" (2018, p. 170) is needed to negotiate the very problematic issues of power - control, content, and consequences - so as to co-create a national 
assessment that reflects the knowledge and skills that can reasonably be attained by beginning WL teachers over the course of a four- or five-year undergraduate or Master of Arts in Teaching program of study and which will position them to be successful working with diverse learners across diverse instructional levels and contexts.

\section{Acknowledgements}

The authors would like to thank Marty Abbott, ACTFL's former Executive Director, and Howie Berman, ACTFL's new Executive Director, for their leadership as well as the World Language edTPA Task Force members Anne Belcher, Maria C. Bustamante, Sarah Jourdain, Terry Osborn, Karen Tharrington, and Pam Wesely. We are also grateful to WL teacher educators who completed the survey, to the reviewers and to Anne Nerenz, the Foreign Language Annals Editor, who gave invaluable feedback.

\section{References}

American Association of Colleges for Teacher Education. (2018). State edTPA policy overview. Retrieved February 11, 2019 from, https://secure.aacte.org/apps/rl/res_get.php?fid=1014\&ref=edtpa

American Association of Colleges for Teacher Education. (2019). Participation map. Retrieved June 7, 2019 from, http://edtpa.aacte.org/state-policy

An, S. (2017). Preparing elementary school teachers for social studies instruction in the context of edTPA. The Journal of Social Studies Research, 41(1), 25-35. 
$\mathrm{Au}, \mathrm{W}$. (2013). What's a nice test like you doing in a place like this? The edTPA and corporate education "reform.” Rethinking Schools, 27(4), 22-27.

Behney, J. (2016). Perceived influence of cooperating teachers on edTPA performance. Foreign Language Annals, 49, 271-286.

Castellano, K. E., Duckor, B., \& Wihardini, D. (2016). Assessing academic language in an elementary mathematics teacher licensure exam. Teacher Education Quarterly, 43(1), 327.

Cochran-Smith, M. (2001). Constructing outcomes in teacher education: Policy, practice, and pitfalls. Education Policy Analysis Archives, 9(11). Retrieved February 11, 2019 from, https://epaa.asu.edu/ojs/article/view/340/466

Cochran-Smith, M., Cummings Carney, M., Stringer Keefe, E., Burton, S., Chang, W. C., Fernández, M. B., Miller, A.F., Sánchez, J. G., \& Baker, M. (2018). Reclaiming accountability in teacher education. New York: Teachers College Press.

Croft, S. J., Robbins, M. A., \& Stenhouse, V. L. (2013). The perfect storm of education reform: High-stakes testing and teacher evaluation. Justice Journal, 42(1), 70-92.

Davis, K., \& Armstrong, A. (2018). Teacher educators' initial impressions of the edTPA: A "love-hate" relationship. SRATE Journal, 27(2), 18-25.

Garcia, P., Moser, K. \& Davis-Wiley, P. (2019). Facing reality: A survey of methods instructors' perspectives on world language teacher development. Foreign Language Annals, 52(8), 165-183.

Greenblatt, D. (2016). The consequences of edTPA. Educational Leadership, 73, 51-54. 
Heil, L., \& Berg, M. H. (2017). Something happened on the way to completing the edTPA: A case study of teacher candidates' perceptions of the edTPA. Contributions to Music Education, 42, 181-199.

Hildebrandt, S. A., \& Hlas, A. C. (2013). Assessing the effectiveness of new teachers with edTPA. The Language Educator, 8(3), 50-51.

Hildebrandt, S. A., \& Swanson, P. (2014). World language teacher candidate performance on edTPA: An exploratory study. Foreign Language Annals, 47, 576-591.

Hildebrandt, S. A., \& Swanson, P. (2016). Understanding the world language edTPA: Researchbased policy and practice. Charlotte, NC: Information Age Publishing.

Hildebrandt, S. A., \& Swanson, P. (In press). Re-examining teacher candidate performance on World Language edTPA as a consequential assessment. NECTFL Review.

Hutt, E.L., Gottlieb, J., \& Cohen, J. (2018). Diffusion in a vacuum: edTPA, legitimacy, and the rhetoric of teacher professionalization. Teaching and Teacher Education, 69, 52-61.

Jourdain, S. (2018a). Native / heritage Spanish-speakers and edTPA. In P. Swanson \& S. A. Hildebrandt (Eds.), Researching edTPA promises and problems: Perspectives from English as an additional language, English language arts, and world language teacher education (pp. 67-86). Charlotte, NC: Information Age Publishers, Inc.

Jourdain, S. (2018b). Who is allowed to teach Spanish in our public schools?: Documenting the consequences of the edTPA. Rethinking Schools, 32(2). Retrieved February 11, 2019 from, https://www.rethinkingschools.org/articles/who-is-allowed-to-teach-spanish-in-ourpublic-schools 
Kissau, S., \& Algonzinne, B. (2017). Effective foreign language teaching: Broadening the concept of content knowledge. Foreign Language Annals, 50, 114-134.

Madeloni, B., \& Gorlewski, J. (2013). Wrong answer to the wrong question: Why we need critical teacher education, not standardization. Rethinking Schools, 27, 4. Available from, http://www.rethinkingschools.org/archive/27_04/27_04_madeloni-gorlewski.shtml

National Commission on Excellence in Education. (1983). A nation at risk : the imperative for educational reform: A report to the Nation and the Secretary of Education, United States Department of Education. Washington, D.C.: The Commission.

No Child Left Behind Act of 2001, P.L. 2017-119, 20 U.S.C. $§ 6319$ (2002).

Okraski, C. V., \& Kissau, S. P. (2018). Impact of content-specific seminars on candidate edTPA preparation and performance. Foreign Language Annals, 51, 685-705.

Pearson. (2018). edTPA scorer qualifications. Available from, http://scoreedtpa.pearson.com/become-an-edtpa-scorer/edtpa-scorer-qualifications.html

Picower, B., \& Marshall, A. M. (2017). "Run like hell” to "look before you leap": Teacher educators' responses to preparing teachers for diversity and social justice in the wake of edTPA. In J. H. Carter \& H. A. Lochte (Eds.), Teacher performance assessment and accountability reforms: The impact of edTPA on teaching and schools. New York: Palgrave Macmillan.

Pringle, B. (2019, January 3). Student debt surges to new records in 2018. Washington Examiner. Available from, https://www.washingtonexaminer.com/red-alert-politics/student-debtsurges-to-new-records-in-2018 
Russell, V., \& Davidson Devall, K. F. (2016). An examination of the edTPA portfolio assessment and other measures of teacher preparation and readiness. Foreign Language Annals, 49, 479-501.

Russell, V., \& Davidson Devall, K. F. (2018). Native and non-native English speaker perceptions of the world language edTPA. In P. Swanson \& S. A. Hildebrandt (Eds.), Researching edTPA promises and problems: Perspectives from English as an additional language, English language arts, and world language teacher education (pp. 23-48). Charlotte, NC: Information Age Publishers, Inc.

Sato, M. (2014). What is the underlying conception of teaching of the edTPA? Journal of Teacher Education, 65, 421-434.

Stanford Center for Assessment, Learning, and Equity. (2015). Educative assessment \& meaningful support: 2014 edTPA administrative report. Retrieved February 11, 2019 from, https://secure.aacte.org/apps/rl/res_get.php?fid=2183\&ref=edtpa

Stanford Center for Assessment, Learning, and Equity. (2016). Educative assessment \& meaningful support: 2015 edTPA administrative report. Retrieved February 11, 2019 from, https://secure.aacte.org/apps/rl/res_get.php?fid=3013\&ref=rl

Stanford Center for Assessment, Learning, and Equity. (2017a). edTPA world language assessment handbook. Stanford, CA: Stanford University.

Stanford Center for Assessment, Learning, and Equity. (2017b). Educative assessment \& meaningful support: 2016 edTPA administrative report. Retrieved February 11, 2019 from, https://secure.aacte.org/apps/rl/res_get.php?fid=3621\&ref=rl 
Stanford Center for Assessment, Learning, and Equity. (2018). Educative assessment \& meaningful support: 2017 edTPA administrative report. Retrieved February 11, 2019 from, https://secure.aacte.org/apps/rl/res_get.php?fid=4271\&ref=edtpa

Swanson, P., \& Hildebrandt, S. (2017). Communicative learning outcomes and world language edTPA: Characteristics of high-scoring portfolios. Hispania, 100, 331-347.

Swanson, P., \& Hildebrandt, S. A. (Eds.). (2018). Researching edTPA promises and problems: Perspectives from English as an additional language, English language arts, and world language teacher education. Charlotte, NC: Information Age Publishing.

Swanson, P., \& Mason, S. (2018). The world language teacher shortage: Taking a new direction. Foreign Language Annals, 51, 251-262.

The National Standards Collaborative Board. (2015). World-readiness standards for learning languages (4th ed.). Alexandria, VA: Author.

Troyan, F. J., \& Kaplan, C. S. (2015). The functions of reflection in high-stakes assessment of world language teacher candidates. Foreign Language Annals, 48, 372-393.

U. S. Department of Education (2017). Teacher shortage areas nationwide listing, 1990-1991 through 2017-2018. Retrieved from http://www2.ed.gov/about/offices/list/ope/pol/ateachershortageareasreport2017-18.pdf.

Youngs, P., \& Whittaker, A. (2015). The role of edTPA in assessing content specific instructional practices. In P. Youngs \& J. Grissom (Eds.), Improving teacher evaluation systems (pp. 89-101). New York, NY: Teachers College Press. 
Participants indicated that they were from the following states: Alabama, California, Colorado, Connecticut, Delaware, Georgia, Iowa, Illinois, Louisiana, Maine, Michigan, Minnesota, North Carolina, New Jersey, New York, Ohio, Oregon, Pennsylvania, and South Carolina. 